\title{
Effect of Low-Level Laser Therapy on Peri-Miniscrew Fluid Prostaglandin E2 and Substance P Levels: A Controlled Clinical Trial
}

\author{
Özer Alkan' (D), Yeşim Kaya² (D), Esra Yüksek² (D), Ahmet Ufuk Kömüroglu³ (D)
}

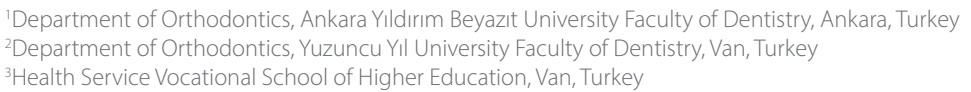

Cite this article as: Alkan Ö, Kaya Y, Yüksek E, Kömüroglu AU. Effect of Low-Level Laser Therapy on Peri-Miniscrew Fluid Prostaglandin E2 and Substance P Levels: A Controlled Clinical Trial. Turk J Orthod 2021; 34(1): 26-30.

Main points:

- Inflammation, which can damage the bone surrounding the neck of the miniscrew, is one of the main causes of miniscrew loosening.

- In this study, the biostimulatory effects of low-level laser therapy were evaluated for its clinical efficacy.

- It was concluded that gallium-aluminum-arsenide diode laser therapy has no effect on inflammation and pain around the miniscrews.

\begin{abstract}
Objective: This study aims to evaluate the effect of low-level laser therapy on peri-miniscrew fluid prostaglandin E2 (PGE2) and substance $\mathrm{P}(\mathrm{SP})$ levels during orthodontic treatment.

Methods: A total of 15 individuals were included in this study. Miniscrews were inserted to the inter-radicular region of the maxillary right and left second premolar and the first molar teeth, and diode lasers were randomly applied to the right or left side. Irradiation was performed at $940 \mathrm{~nm}$ wavelength using a gallium-aluminum-arsenide diode laser with $100 \mathrm{~mW}$ power output, $0.125 \mathrm{~cm} 2 \mathrm{spectral}$ area, $8 \mathrm{~J} / \mathrm{cm} 2$ energy density, and 10 seconds of exposure time. Peri-miniscrew fluid samples were collected on the $1 \mathrm{st}$, 3rd, and 7th days, and PGE2 and SP levels were assessed. For statistical comparison, two-way (factors) analysis of variance with repeated measurements on one-factor levels was used at statistical significance $(p)$ of $<0.05$.
\end{abstract}

Results: PGE2 levels on the 1st, 3rd, and 7th days were $160.64 \pm 10.05,135.17 \pm 37.18$, and $98.57 \pm 22.94$, respectively, in the control group and $150.75 \pm 9.08,87.17 \pm 40.67$, and $78.10 \pm 16.50$, respectively, in the laser group. SP levels on the $1 \mathrm{st}$, 3rd, and 7 th days were $79.90 \pm 12.05,64.61 \pm 10.05$, and $70.05 \pm 9.10$, respectively, in the control group and $76.32 \pm 11.39,60.25 \pm 9.08$, and $65.71 \pm 5.59$, respectively, in the laser group. The differences in PGE2 and SP levels between the laser and control groups were not statistically significant at all time intervals.

Conclusion: Low-level laser therapy cannot be recommended as a clinical adjunct therapy to reduce inflammation and pain around the miniscrews.

Keywords: Inflamation, miniscrew, pain, PGE2, SP

\section{INTRODUCTION}

Anchorage, which has a critical role in the success of orthodontic treatment, is defined as resistance to undesired tooth movement (1). Because the use of traditional anchorage enhancement methods, such as headgear and intra-oral elastic, are patient dependent, the use of dental implants, miniplates, and miniscrews that require less patient cooperation have become more widespread $(2,3)$. In addition, miniscrews have advantages over miniplates and dental implants, such as their small size, availability of many inserting regions in the oral cavity, low cost, and easy application and removal (4). However, early loss is the most common clinical challenge in using miniscrews (5).

Address for Correspondence: Yeşim Kaya, Department of Orthodontics, Yuzuncu Yıl University Faculty of Dentistry 
Inflammation, which can damage the bone surrounding the neck of the miniscrew, is one of the main causes of miniscrew loosening $(6,7)$. Immediately after miniscrew insertion, the traumatized area suffers ischemic injury and deficiency of nutrients and oxygen supply, which may cause apoptosis of the injured cells $(8,9)$. To achieve tissue integrity, the healing process must include an inflammatory response and tissue formation and remodeling (8).

The use of low-level laser therapy, carried out with appropriated protocols, increases collagen synthesis and fibroblast proliferation and influences cellular and subcellular processes needed to increase the formation of messenger RNA, adenosine triphosphate synthesis, and lymphocytic action to initiate and promote the healing process $(10,11)$. Furthermore, low-level laser therapy decreases inflammatory reactions and pain by increasing local blood circulation, inhibiting inflammatory substance secretion, inducing neurotransmitter release, altering the conduction and excitation of the peripheral nerves, and stimulating endorphin release $(12,13)$.

Clinical, histological, biomechanical, and biochemical examinations are based on the evaluation of miniscrew stabilization. Biochemical examination is a non-invasive and simple method in which the peri-miniscrew fluid is used for evaluating the buildup and destructive levels of the tissues surrounding the miniscrew (14). Only 1 study in the literature has used biochemical assessments to explore the effect of low-level laser therapy on miniscrew stability (15). In this study, interleukin-6 (IL-6) levels elevated in the later stage of the inflammatory response were explored. Furthermore, IL-8 levels, which can be detected at high levels in healthy and diseased periodontal tissues, were analyzed (16). However, no study has evaluated prostaglandin $E_{2}\left(P G E_{2}\right)$ and substance $P(S P)$ levels. $P G E_{2}$ is known to affect the fibroblasts and osteoclasts that induce the synthesis of IL-1 $\beta$ and other cytokines. In addition, SP released from nerve endings plays an important role in inflammation $(17,18)$.

In light of this information, we aimed to study the effect of low-level laser therapy on peri-miniscrew $\mathrm{PGE}_{2}$ and SP levels, which are important cytokines in the inflammatory and pain responses. The alternative hypothesis was that low-level laser therapy may reduce inflammation and pain around the miniscrews.

\section{METHODS}

A total of 15 individuals to be treated with fixed orthodontic appliances at Van Yüzüncü Yıl University, Faculty of Dentistry, Department of Orthodontics, were included in this study. The following inclusion criteria were applied: no previous fixed orthodontic treatments, cephalometric evaluation and model analysis indicating upper 2 premolar teeth extraction, good general health conditions, healthy periodontal tissues, and individuals younger than 18 years with completed permanent dentition. Individuals who were pregnant or lactating, had used antibiotics within the previous 6 months, and had poor oral hygiene were excluded from the study.
The study was conducted after the approval of Van Yüzüncü Yıl University, Faculty of Medicine, Ethics Committee (08.10.2015/07). After a detailed explanation of the study, informed consent was obtained from all participants.

Miniscrews (ACR, Seoul, Korea, $1.6 \mathrm{~mm}$ wide, $7 \mathrm{~mm}$ length) were inserted in the inter-radicular region of the maxillary right and left second premolar and molar teeth (19). Stainless steel wire ( 0.017 inch $\times 0.025$ inch) was passively bent between the miniscrew and auxiliary tube of the maxillary first molar to increase the anchorage in the posterior region. Subsequently, maxillary first premolar teeth extractions were performed, and fixed orthodontic treatment using 0.018-slot Roth brackets (Victory Series, 3M Unitek, Monrovia, California) was carried out.

The upper jaws of patients irradiated by the diode laser represented the laser group, and patients with non-irradiated jaws represented the control group. The sealed-envelope technique was used to select whether the right or left side would be irradiated. The soft tissue surrounding the miniscrew was irradiated with a $940 \mathrm{~nm}$ wavelength of gallium-aluminum-arsenide diode laser with $100 \mathrm{~mW}$ power output, $0.125 \mathrm{~cm}^{2} \mathrm{spec}$ tral area, $8 \mathrm{~J} / \mathrm{cm}^{2}$ energy density, and 10 seconds of exposure time (Figure1). The tip was held perpendicular and in contact with the mucosa during the laser procedure. Diode laser irradiation was applied by a single investigator over the miniscrew insertion area on the buccal and palatinal surfaces on days 1 , 3 , and 7 .

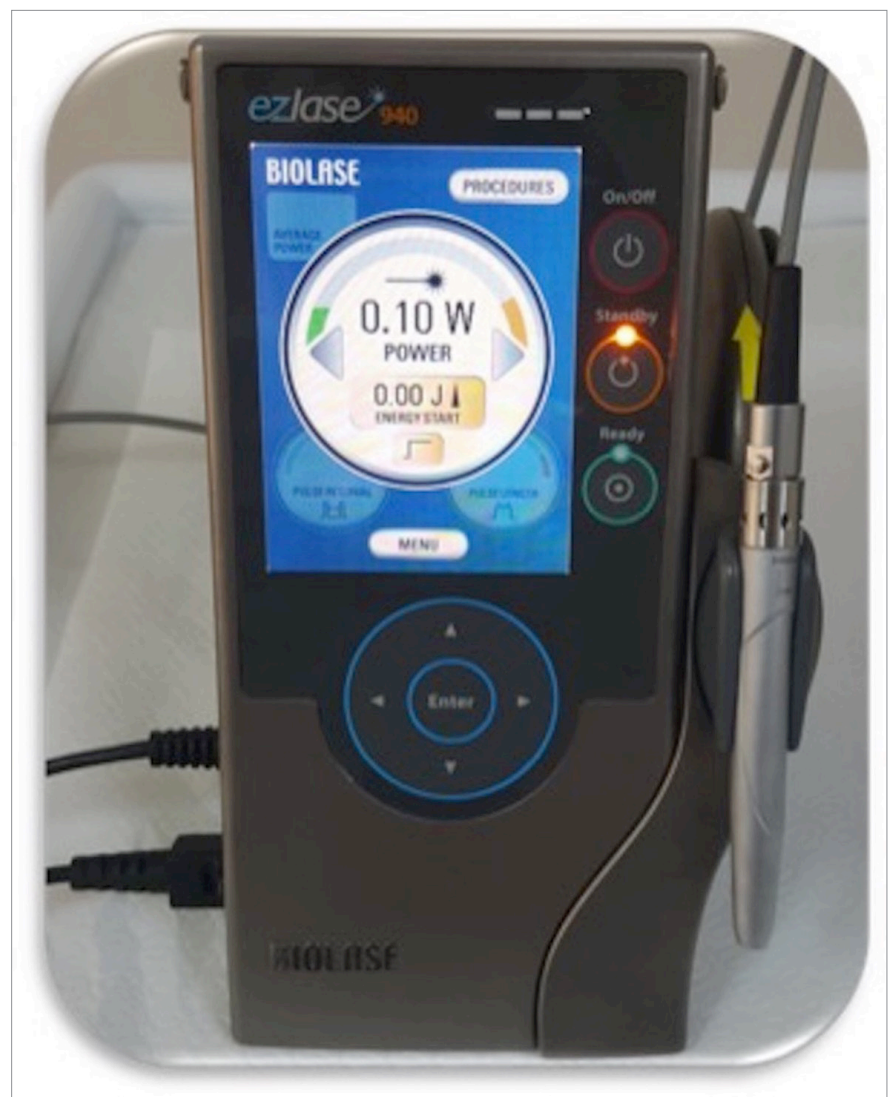

Figure 1. Diode laser device 


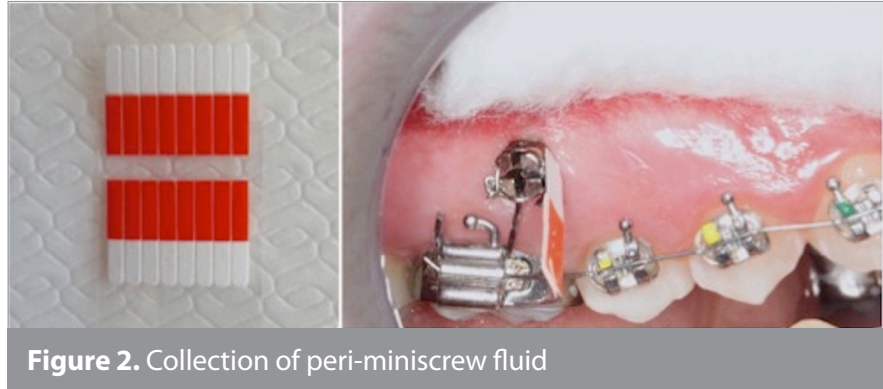

Table 1. Descriptive statistics for patient age (years)

\begin{tabular}{|lccccc|}
\hline & $\mathbf{n}$ & $\begin{array}{c}\text { Age } \\
(\mathbf{m e a n} \pm \text { SD) }\end{array}$ & Maximum & Minimum & $\mathbf{p}$ \\
\hline Female & 8 & $17.40 \pm 1.45$ & 18 & 14 & 0.495 \\
Male & 7 & $16.85 \pm 1.57$ & 18 & 14 & \\
Total & 15 & $17.15 \pm 1.48$ & 18 & 14 & \\
\hline \multicolumn{5}{l}{ SD: Standard deviation }
\end{tabular}

Table 2. $P G E_{2}$ levels $(\mathrm{pg} / \mathrm{mL})$ in control and laser groups

\begin{tabular}{|lccc|}
\hline & $\begin{array}{c}\text { Control group } \\
\text { (mean } \pm \text { SD) }\end{array}$ & Laser group & p \\
\hline $1^{\text {st }}$ day & $160.64 \pm 10.05$ & $150.75 \pm 9.08$ & 0.915 \\
$3^{\text {rd }}$ day & $135.17 \pm 37.18$ & $87.17 \pm 40.67$ & 0.397 \\
$7^{\text {th }}$ day & $98.57 \pm 22.94$ & $78.10 \pm 16.50$ & 0.478 \\
\hline *Two-way (factors) analysis of variance with repeated measurements on \\
$\begin{array}{l}\text { *ne-factor levels (interaction is not statistically significant) } \\
\text { PGE }: \text { prostaglandin E2; SD: Standard deviation }\end{array}$ \\
\hline
\end{tabular}

Table 3. SP levels $(\mathrm{pg} / \mathrm{mL})$ in control and laser groups

\begin{tabular}{|lccc|}
\hline & $\begin{array}{c}\text { Control group } \\
(\mathbf{m e a n} \pm \mathbf{S D})\end{array}$ & Laser group & p \\
\hline $1^{\text {st }}$ day & $79.90 \pm 12.05$ & $76.32 \pm 11.39$ & 0.833 \\
$3^{\text {rd }}$ day & $64.61 \pm 10.05$ & $60.25 \pm 9.08$ & 0.483 \\
$7^{\text {th }}$ day & $70.05 \pm 9.10$ & $65.71 \pm 5.59$ & 0.703 \\
\hline *Two-way (factors) analysis of variance with repeated measurements on \\
$\begin{array}{l}\text { *ne-factor levels (interaction is not statistically significant) } \\
\text { SP: Substance P; SD: Standard deviation }\end{array}$ \\
\hline
\end{tabular}

Peri-miniscrew fluid samples were collected on the $1^{\text {st }}, 3^{\text {rd }}$, and $7^{\text {th }}$ days by placing paper strips of standard size (Periopaper, Gingival Fluid Collection Strips, Oraflow, Smithtow, NY, 11787) onto the mesiobuccal and distobuccal regions of the miniscrew. During the sampling process, the region was dried with sprayed air for a short time and then isolated with cotton rolls to avoid contamination from saliva and blood (Figure 2). The samples contaminated with blood and exudate were excluded from the study. All periopapers were kept in the crevice for 30 seconds and then put into sterile Eppendorf tubes containing $500 \mu \mathrm{L}$ phosphate-buffered saline $\left(\mathrm{pH} \mathrm{7.0)}\right.$ ) and stored at $-40^{\circ} \mathrm{C}$ until the day of analysis.

A PGE ${ }_{2}$ Enzyme Immunoassay (EIA) kit and an SP EIA kit (Cayman Chemicals, AnnArbor, MI) were used to determine $\mathrm{PGE}_{2}$ and SP levels. Analysis of samples was carried out according to the manufacturer's recommended protocol using enzyme-linked immu- nosorbent assay method. Peri-miniscrew fluid samples were collected from the laser and control groups on days 1,3, and 7. The stability of miniscrews at all time intervals was also evaluated clinically, and no failure was observed.

\section{Statistical Analysis}

\section{Sample size calculation}

Because the standard deviation (SD) (s) of IL-1 $\beta$ levels ranged from 2.5 to $3.2 \mathrm{pg} / \mathrm{mL}$ in a previous study, this study established these levels as $2.8 \mathrm{pg} / \mathrm{mL}$ (20). Furthermore, for the 0.05 type I error rate, the effect size and $Z$ value were assumed to be 1.5 and 1.96 , respectively. On the basis of this information and according to the sample size equation $\left(n=Z^{2} s^{2} / d^{2}\right)$, the minimum sample size was calculated to be 13.38 (@13). To account for a $20 \%$ follow-up loss, we rounded up the number to 15 participants.

The Statistical Package for the Statistical Package for Social Sciences version 23.0 software (IBM Corp.; Armonk, NY, USA) was used for statistical analysis. The results were expressed as means and SD, as well as maximum and minimum values. The Kolmogrov-Smirnov test was applied to assess whether the data were normally distributed. To compare the groups (independent factors: control and laser) and time (dependent factors: $1^{\text {st }}, 3^{\text {rd }}$, and $7^{\text {th }}$ days), two-way (factors) analysis of variance with repeated measurements on one-factor level was performed. The significance level in the calculations was taken as $5 \%$.

\section{RESULTS}

A total of 8 patients in the study group were women (mean age: 17.40 years, SD: 1.45 years) and 7 men (mean age: 16.85 years, SD: 1.57 years). There was no statistically significant difference between sexes in terms of mean age and patient count (Table 1).

In the control group, means and SDs of $\mathrm{PGE}_{2}$ levels were $160.64 \pm 10.05 \mathrm{pg} / \mathrm{mL}, 135.17 \pm 37.18 \mathrm{pg} / \mathrm{mL}$, and $98.57 \pm 22.94 \mathrm{pg} /$ $\mathrm{mL}$ on days 1,3 and 7, respectively. In the laser group, means and SDs of $P_{G E}$ levels were $150.75 \pm 9.08 \mathrm{pg} / \mathrm{mL}, 87.17 \pm 40.67 \mathrm{pg} / \mathrm{mL}$, and $78.10 \pm 16.50 \mathrm{pg} / \mathrm{mL}$ on days 1,3 , and 7 , respectively. The differences in $\mathrm{PGE}_{2}$ levels between the laser and control groups on days 1,3 , and 7 were not statistically significant ( $p>0.05$ ) (Table 2 ).

In the control group, means and SDs of SP levels were $79.90 \pm 12.05$ $\mathrm{pg} / \mathrm{mL}, 64.61 \pm 10.05 \mathrm{pg} / \mathrm{mL}$, and $70.05 \pm 9.10 \mathrm{pg} / \mathrm{mL}$ on days 1,3 , and 7, respectively. In the laser group, means and SDs of SP levels were $76.32 \pm 11.39 \mathrm{pg} / \mathrm{mL}, 60.25 \pm 9.08 \mathrm{pg} / \mathrm{mL}$, and $65.71 \pm 5.59$ $\mathrm{pg} / \mathrm{mL}$ on days 1,3 , and 7 , respectively. The differences in SP levels between the laser and control groups were not statistically significant (Table 3).

\section{DISCUSSION}

The results of this study that investigated the effect of low-level laser therapy on peri-miniscrew $\mathrm{PGE}_{2}$ and $\mathrm{SP}$ levels led to insignificant differences between the laser and control groups. Therefore, the alternative hypothesis was fully rejected. 
In recent years, the application of low-level lasers has become popular for their biostimulatory effects, such as acceleration of healing, reduction of inflammation, and alleviation of pain (21). The biostimulatory effect might be influenced by the optical properties of tissues and the type, wavelength, energy density, power, and exposure time of the lasers (22). The gingiva contains fibrous connective tissue and associated extracellular matrix components, as well as a high content of water and melanin (23). Moreover, deeper penetration of the lasers into the soft tissue depends on the wavelength or low absorption coefficient in water (21). Therefore, among the carbon dioxide $\left(\mathrm{CO}_{2}\right)$, neodymium: yttrium-aluminum-garnet, and diode lasers that could be used in soft tissues, we preferred diode lasers in our study because of their low absorption coefficient in water compared with that of the $\mathrm{CO}_{2}$ laser, good absorption by pigmented tissue, and selective targeting of inflamed tissue $(23,24)$.

The most suitable wavelength range for biostimulation is reported to be 600-1,000 nm $(11,13)$. Moreover, because low-power output and longer exposure time are known to best reduce the inflammatory process and pain, dosages of $1-20 \mathrm{~J} / \mathrm{cm}^{2}$, light powers of $10-100 \mathrm{~mW}$, and durations from 10 seconds to 2.7 minutes irradiation are recommended $(13,25)$. The $940-\mathrm{nm}$ gallium-aluminum-arsenide diode laser used in this study with $100 \mathrm{~mW}$ power output, $8 \mathrm{~J} / \mathrm{cm}^{2}$ energy density, and 10 seconds of exposure time was observed to be within the recommended ranges.

Although the measurement intervals of peri-miniscrew pro-inflammatory cytokines vary among studies, Sari et al. (20) found a significant increase in IL-1 $\beta$ levels on the $1^{\text {st }}$ day and a decrease to the baseline level on the $7^{\text {th }}$ day. Furthermore, Yanaguizawa et al. (15) reported significant increases in IL-6 and IL-8 levels in the first 3 days, indicating the beginning of inflammatory response. Therefore, in this study, peri-miniscrew fluid evaluations were performed on days 1,3 , and 7 .

Human studies exploring the effect of low-level laser therapy on miniscrew stability exhibit conflicting results. Although miniscrew stability was evaluated clinically in 3 of them, it was examined biochemically through cytokines in 2 studies $(8,11,15,26)$. Osman et al. (8), who evaluated miniscrew stability using a periotest device, concluded that diode laser therapy $(910 \mathrm{~nm}, 0.7 \mathrm{~W}, 60 \mathrm{~s}$ ) can be recommended as a clinical adjuvant to increase the success of miniscrews. Similarly, the results of another study using a periotest device have also shown an increase in the secondary stability of miniscrews after diode laser therapy (635 nm, $100 \mathrm{~mW}, 100 \mathrm{~s}$ ) (11). However, in a study by Abohabib et al. (26), which evaluated miniscrew stability with an Osstell implant stability quotient device, the effect of diode laser therapy ( $940 \mathrm{~nm}, 1.7 \mathrm{~W}, 60 \mathrm{~s}$ ) was not shown to be clinically useful. The controversial findings between the study results might be owing to the different laser parameters and measurement devices. In our study, miniscrew stability was evaluated clinically without a measurement device, and no failures were observed in either group.

When the studies in which miniscrew stability was evaluated biochemically through cytokines were examined, it was determined that among the pro-inflammatory cytokines, IL-1 $\beta, I L-2$, IL-6, and IL-8 were explored $(15,20,27)$. Besides, only in the study by Yanaguizawa et al. (15) evaluating IL- 6 and IL-8 levels, the effect of diode laser therapy $(660 \mathrm{~nm}, 40 \mathrm{~mW}, 1 \mathrm{~min}, 2.4 \mathrm{~J}$ of total energy) on initial infection was examined at 24,48 , and 72 hours. The results showed a significant increase in IL-8 levels in the control group at all time intervals, as well as an increase in IL- 6 levels in the laser group 24 hours after miniscrew application (15).

No study in the literature has evaluated the peri-miniscrew $\mathrm{PGE}_{2}$ and SP levels after laser therapy. In our study, the effect of gallium-aluminum-arsenide diode laser therapy $(940 \mathrm{~nm}, 100 \mathrm{~mW}$,

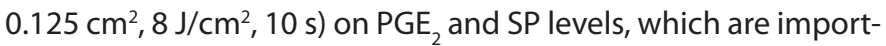
ant cytokines in inflammation and pain, was evaluated at 1, 3, and 7 days. As a result, insignificant differences were determined between the laser and control groups at all time intervals.

A short observation period, small sample size, and lack of information on the clinical periodontal status of patients were the main limitations of this study. Therefore, further studies involving a larger sample size and a longer follow-up period and using different laser wavelengths, energy densities, application periods, and protocols are recommended.

\section{CONCLUSION}

Although a decrease in $\mathrm{PGE}_{2}$ and SP levels was observed in the laser group, the differences between the groups were not statistically significant. Considering the limitations of this study, it appears that gallium-aluminum-arsenide diode laser therapy has no effect on inflammation and pain around the miniscrews, which was evaluated by means of PGE 2 and SP levels.

Ethics Committee Approval: This study was approved by Ethics committee of Van Yüzüncü Yıl University, (Approval No:TSA-20186757).

Informed Consent: Written informed consent was obtained from the patients who agreed to take part in the study.

Peer-review: Externally peer-reviewed.

Author Contributions: Supervision -Y.K., Ö.A.; Design - Y.K., Ö.A., E.Y.; Supervision - Y.K., Ö.A.; Resources - E.Y., Y.K.; Materials - E.Y., Y.K.; Data Collection and/or Processing - E.Y., A.U.K.; Analysis and/or Interpretation - Ö.A., Y.K.; Literature Search - Ö.A., Y.K.; Writing Manuscript - Ö.A., Y.K.; Critical Review - Ö.A., Y.K.

Conflict of Interest: The authors have no conflict of interest to declare.

Financial Disclosure: The authors declared that this study has received no financial support.

\section{REFERENCES}

1. Schnelle MA, Beck FM, Jaynes RM, Huja SS. A Radiographic evaluation of the availability of bone for placement of miniscrews. Angle Orthod 2004; 74: 832-7.

2. Kuroda S, Sugawara Y, Deguchi T, Kyung HM, Takano-Yamamoto T. Clinical use of miniscrew implants as orthodontic anchorage: Success rates and postoperative discomfort. Am J Orthod Dentofacial Orthop 2007; 131: 9-15. [Crossref]

3. Bittencourt LP, Raymundo MV, Mucha JN. The optimal position for insertion of orthodontic miniscrews. Revista Odonto Ciência 2011; 26: $133-8$. 
4. Poggio PM, Incorvati C, Velo S, Carano A. "Safe Zones": a guide for miniscrew positioning in the maxillary and mandibular arch. Angle Orthod 2006; 76: 191-7.

5. Goymen M, Isman E, Taner L, Kurkcu M. Histomorphometric evaluation of the effects of various diode lasers and force levels on orthodontic mini screw stability. Photomed Laser Surg 2015; 33: 29-34. [Crossref]

6. Miyawaki S, Koyama I, Inoue M, Mishima K, Sugahara T, Takano-Yamamoto T. Factors associated with the stability of titanium screws placed in the posterior region for orthodontic anchorage. Am J Orthod Dentofacial Orthop 2003; 124: 373-8. [Crossref]

7. Antoszewska J, Papadopoulos MA, Park HS, Ludwig B. Five-year experience with orthodontic miniscrew implants: a retrospective investigation of factors influencing success rates. Am J Orthod Dentofacial Orthop 2009; 136: 158.E1-158.E10. [Crossref]

8. Osman A, Moneim AA, Harouni NE, Shokry M. Long-term evaluation of the effect of low-level laser therapy on orthodontic miniscrew stability and peri-implant gingival condition: A randomized clinical trial. J World Fed Orthod 2017; 6: 109-4. [Crossref]

9. Garcez AS, Suzuki SS, Martinez EF, Lemini MG, Suzuki H. Effects of low-intensity laser therapy over mini-implants success rate in pigs. Lasers Med Sci 2015; 30: 727-32. [Crossref]

10. Pinheiro AL. Advances and perspectives on tissue repair and healing. Photomed Laser Surg 2009; 27: 833-6. [Crossref]

11. Flieger R, Gedrange $T$, Grzech Leśniak K, Dominiak M, Matys J. Low-level laser therapy with a $635 \mathrm{~nm}$ diode laser affects orthodontic mini-implants stability. A randomized Clinical split-mouth trial. $J$ Clin Med 2019; 9: 112-23. [Crossref]

12. Qamruddin I, Alam MK, Fida M, Khan AG. Effect of a single dose of low-level laser therapy on spontaneous and chewing pain caused by elastomeric separators. Am J Orthod Dentofacial Orthop 2016; 149: 62-6. [Crossref]

13. Almallah MME, Almahdi WH, Hajeer MY. Evaluation of low level laser therapy on pain perception following orthodontic elastomeric separation: A randomized conrolled trial. J Clin Diagn Res 2016; 10: 23-8. [Crossref]

14. Intachai I, Krisanaprakornkit $S$, Kongtawelert P, Ong-chai S, Buranastidporn B, Suzuki EY, et al. Chondroitin sulphate (WF6 epitope) levels in peri-miniscrew implant crevicular fluid during orthodontic loading. Eur J Orthod 2010; 32: 60-5. [Crossref]

15. Yanaguizawa MS, Suzuki SS, Martinez EF, Suzuki H, Pelegrin MCJ, Garcez AS. Effects of low-level laser therapy in orthodontic patients on immediate inflammatory response after mini-implants inser- tion: A preliminary report. Photomed Laser Surg 2017; 35: 57-63. [Crossref]

16. McGee JM, Tucci MA, Edmundson TP, Serio CL, Johnson RB. The relationship between concentrations of proinflammatory cytokines within gingiva and the adjacent sulcular depth. J Periodontol 1998; 69: 865-71. [Crossref]

17. Dongari-Bagtzoglou Al, Ebersole JL. Production of inflammatory mediators and cytokines by human gingival fibroblasts following bacterial challenge. J Periodontal Res 1996; 31: 90-8. [Crossref]

18. de Avila ED, de Molon RS, de Godoi Gonçalves DA, Camparis CM. Relationship between levels of neuropeptide Substance $P$ in periodontal disease and chronic pain: a literature review. J Investig Clin Dent 2014; 5: 91-7. [Crossref]

19. Omasa S, Motoyoshi M, Arai Y, Ejima K, Shimizu N. Low- level laser therapy enhances the stability of orthodontic mini-implants via bone formation related to BMP-2 expression in a rat model. Photomed Laser Surg 2012; 30: 255-61. [Crossref]

20. Sari E, Uçar C. Interleukin 1 beta levels around microscrew implants during orthodontic tooth movement. Angle Orthod 2007; 77: 10738. [Crossref]

21. Aoki A, Mizutani K, Schwarz F, Sculean A, Yukna RA, Takasaki AA, et al. Periodontal and peri-implant wound healing following laser therapy. Periodontol 2000; 68: 217-69. [Crossref]

22. Akyol G, Baser U, Maden I, Kazak Z, Onan U, Tanrikulu-Kucuk S, et al. The effect of low-level laser therapy as an adjunct to non-surgical periodontal treatment. J Periodontol 2011; 82:481-88. [Crossref]

23. Cobb CM. Lasers in periodontics: A review of the literature. J Periodontol 2006; 77: 545-64. [Crossref]

24. Katsikanis F, Strakas D, Vouros I. The application of antimicrobial photodynamic therapy (aPDT, $670 \mathrm{~nm}$ ) and diode laser $(940 \mathrm{~nm})$ as adjunctive in the conventional cause-related treatment of chronic periodontal diseases: a randomized controlled split-mouth clinical trial. Clin Oral Investig 2020; 24: 1821-7. [Crossref]

25. Eslamian L, Borzabadi-Farahani A, Hassanzadeh-Azhiri A, Badiee MR, Fekrazad R. The effect of 810-nm low-level laser therapy on pain caused by elastomeric separators. Lasers Med Sci 2014; 29: 559-64. [Crossref]

26. Abohabib AM, Fayed MM, Labib AH. Effects of low-intensity laser therapy on the stability of orthodontic mini-implants: A randomised controlled clinical trial. J Orthod 2018; 45: 149-56. [Crossref]

27. Hamamcı N, Acun Kaya F, Uysal E, Yokuş B. Identification of interleukin 2, 6, and 8 levels around miniscrews during orthodontic tooth movement. Eur J Orthod 2012; 34: 357-61. [Crossref] 